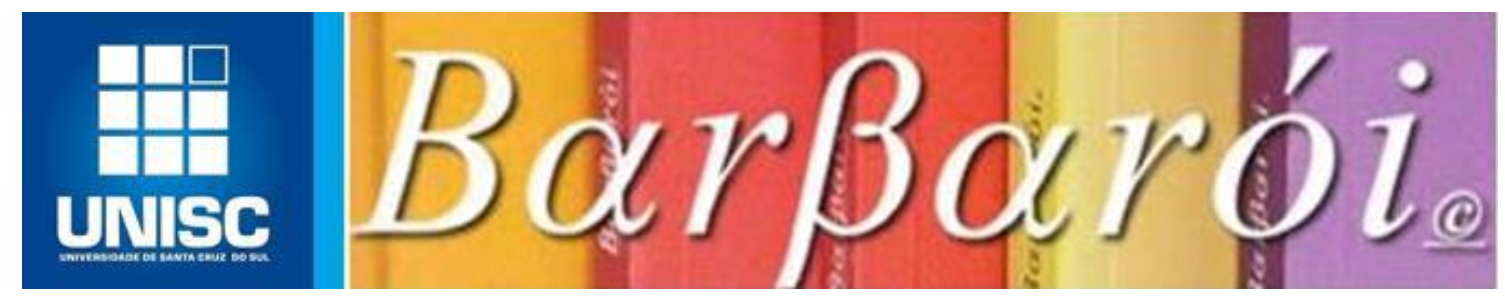

\title{
“MEU CORPO FOI RECONHECIDO PELO ESTADO": AS CONTROVÉRSIAS EM TORNO DA DESJUDICIALIZAÇÃO DO DIREITO À IDENTIDADE
}

\section{DOI: http://dx.doi.org/10.17058/barbaroi.v0i0.14594}

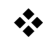 \\ Gabriela Felten da Maia \\ Universidade Federal do Rio Grande do Sul-UFRGS - Brasil
}

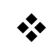

\begin{abstract}
Resumo
O contexto brasileiro é marcado por uma lacuna legislativa para o acesso às retificações de registro civil para pessoas trans. A decisão do Supremo Tribunal Federal, em março de 2018, trouxe uma nova possibilidade diante da ausência de marco regulatório nacional para o processo de retificação de registro civil. Essa decisão modifica o cenário com a retirada da tutela jurídica e médica, possibilitando o acesso a uma gama mais ampla de sujeitos que desejam retificar, mas não necessariamente passar por cirurgia ou entrevistas diagnósticas para obter um laudo. Com isso, entende-se que se trata de um avanço no reconhecimento estatal da diversidade de gênero. Nesse sentido, o objetivo desse trabalho é apresentar algumas questões iniciais que emergem do trabalho de campo de doutorado a respeito da transformação no processo de regulação do direito à identidade. Procura-se refletir se desjudialização implica em desburocratização.
\end{abstract}

Palavras-chave:

Pessoas Trans; Direito à Identidade; Desjudicialização.

\section{Introdução}

O contexto brasileiro é marcado por uma lacuna legislativa para o acesso às retificações de registro civil para pessoas trans ${ }^{1}$. Por muito tempo o processo foi realizado via judiciário, a partir de encaixes entre medicina e direito, como avaliam Ventura (2007), Coacci

\footnotetext{
${ }^{1}$ Os esforços por categorias de identificação da população trans tanto no plano político quando científico, o uso de termos é bastante diverso e perpassa as experiências das próprias pessoas que as utilizam para identificaremse. Transexual, travesti e homens trans tem sido as categorias presentes no debate político para explicitar sujeitos de direito e político do movimento social. No cenário político as tensões sobre as categorias identitárias permanecem, entre o uso de um termo que englobe todas as vivências de gênero ou a manutenção das múltiplas identidades. Por isso, tem se fortalecido o uso da noção de pessoas trans como um termo que aglutina a multiplicidade das identidades de gênero e possui um caráter menos patologizante. Nessa tese utitilizar-se-á pessoas trans quando se referir às identidades de forma genérica e, quando necessário, será utilizado termos de identificação que correspondam a autoidentificação de interlocutores. Sobre esse debate ver Carvalho e Carrara (2013), Bagagli (2013) e Jesus (2014).
}

Barbarói, Santa Cruz do Sul, Edição Especial n.54, p.<76-93>,jul./dez. 2019 
(2011; 2018), Lima (2015) e Freire (2015). Essa centralidade do judiciário constituiu-o como uma importante estratégia de luta para visibilidade da demanda de reconhecimento do direito à identidade. Mas a partir de 2018, com a decisão do Supremo Tribunal Federal (STF) sobre a Ação Direta de Inconstitucionalidade (ADI) 4275, o processo passou a ser realizado administrativamente, diretamente nos cartórios.

Essa decisão reconhece a autodeterminação de gênero sob uma perspectiva dos direitos humanos, em que há autonomia das pessoas sobre quem são, não cabendo ao judiciário decidir ou dizer quem a pessoa é. Modifica o cenário de mudança registral, com a retirada da necessidade de provas médicas, fotos, testemunhas, a autorização judicial e as diferentes compreensões de juízes e desembargadores sobre a demanda. Possibilita, desse modo, o acesso a uma gama mais ampla de sujeitos que desejam retificar, mas não necessariamente passar por cirurgia ou entrevistas diagnósticas para obter um laudo.

Esse trabalho aproxima-se de uma abordagem que entende Estado não como uma entidade, mas um conjunto de processos, atenta para a dimensão performativa, o efeito de Estado, que se realiza a partir de práticas e fluxos. Trouillot (2001) aponta que uma etnografia do Estado se torna possível na medida em que não há um campo específico de análise, institucional ou geograficamente, senão um processo aberto em múltiplos níveis e nenhuma fixidez institucional que só podem ser analisados nos vários contextos de vida em que pode reconhecê-lo pelos seus efeito. Para o autor, é na banalidade desses vários encontros entre indivíduos e grupos e o Estado que descobrimos a profundidade do governo em nossas vidas, isto é, "its materiality resides much less in institutions than in the reworking of processes and relations of power so as to create new spaces for the deployment of power" (TROUILLOT, 2001, p. 127).

Acompanhando diferente atores e como mobilizam o direito ao nome e a identidade de gênero interroga-se até que ponto desjudicializar implica em desburocratizar. Se não há mais obrigatoriedade de laudo, as exigências de documentos colocados como facultativos, cobranças de valores altos para emissão de documentos, exposição do nome que consta no registro civil, são alguns dos empecilhos apresentados, fazendo com que muitas pessoas tenham que retornar diversas vezes ao cartório para conseguir retificar. Desde a apresentação de documentos de identificação, certidões, explicações em guichês, recepção de serviços, preenchimento de formulários, entre outros que pessoas trans precisam circular para obter acesso ao nome social ou a retificação registral e ocupam os modos como o cotidiano administrativo das repartições é produzido.

Nesse artigo apresenta um recorte de uma pesquisa de doutorado em andamento com o objetivo de refletir sobre o nascimento de um direito e o processo de reconhecimento da 
identidade de gênero a partir do período após a decisão do STF. Após a decisão do STF observa-se mudanças na forma de regulação. As autoridades judicial, médica e/ou psicológica apareciam como aquelas que tutelavam o direito à identidade e, portanto, a autonomia das pessoas trans. Com a retirada destes há outras autoridades que também constituíam o processo de reconhecimento da identidade e passaram a ganhar centralidade. Na cotidianidade das operações que fazem o Estado, não uma entidade homogênea e totalizante, mas produzido nas práticas, nos detalhes técnicos de implementação das políticas públicas ou nos processos burocráticos que se pode perceber onde reside o poder de regular as populações. Nesse sentido, objetiva-se apresentar a rede de relações e disputas entre agentes, estratégias e objetivos diversos na busca por efetivar um direito.

\section{A desjudicialização do reconhecimento da identidade}

No período de 1970 a 2018, o debate brasileiro no campo médico e jurídico sobre o reconhecimento da identidade de gênero nos documentos de identificação civil esteve baseado na compreensão patologizante do campo médico-psiquiátrico. As decisões pautavam-se a partir da obrigatoriedade da realização de procedimento cirúrgico para, então, ser concedido o direito à identidade. As pessoas que não tivessem realizado ou ainda estariam em processo de transição poderiam ter seus pedidos deferidos ou não conforme a compreensão dos operadores do direito (LIMA, 2015; COACCI, 2018).

O debate no Supremo Tribunal Federal (STF) deu-se através da Ação Direta de Inconstitucionalidade (ADI) $\mathrm{n}^{\circ}$. 4.275 . Apresentada em 2009, essa ação discutia a possibilidade de retificação do nome e gênero no registo civil independente da cirurgia de redesignação sexual, mas condicionada a apresentação de laudo que atestasse a transexualidade. Nessa época, as legislações consideradas modelo de aplicação dos direitos humanos na compreensão do direito a identidade como autodeterminação ainda não havia sido aprovado. O debate sobre despatologização também não havia se desenvolvido no contexto nacional. Por isso, dispensar a cirurgia, nesse momento era um avanço em relação a um judiciário que negava retificações considerando a cirurgia como pré-condição.

Desse modo, tinha como objetivo constituir uma jurisprudência que orientasse as decisões judiciais envolvendo à retificação registral. Nesse documento foi utilizado diversos julgados de Apelação Cível do Tribunal de Justiça do Rio Grande do Sul (TJRS) e do

\footnotetext{
${ }^{2}$ Disponível em:

http://www.stf.jus.br/portal/geral/verPdfPaginado.asp?id=400211\&tipo=TP\&descricao=ADI\%2F4275. Acesso em: 09 de julho de 2016.

Barbarói, Santa Cruz do Sul, Edição Especial n.54, p.<76-93>,jul./dez. 2019
} 
Tribunal Regional Federal da $4^{\mathrm{a}}$ Região (TRF4/RS). Na mesma linha havia um Recurso Extraordinário (RE 670422), aguardando julgamento no STF, interposto questionando a decisão do Tribunal de Justiça do Rio Grande do Sul (TJ-RS) por manter a decisão em primeiro grau da alteração do gênero nos documentos somente acontecer após a realização da cirurgia de redesignação sexual. Os julgamentos dessas duas ações pautavam-se na existência de um direito fundamental à identidade de gênero com base nos princípios constitucionais da dignidade da pessoa humana, da igualdade, da vedação de discriminações odiosas, da liberdade e da privacidade. Por isso, a votação da ação direta de inconstitucionalidade 4275 e do recurso extraordinário 670422 vinham sendo aguardados pela repercussão geral que possuem sobre as ações para retificação registral de pessoas trans.

A votação da ADI 4275 foi acompanhada das arguições de amici curie que buscaram apontar uma outra compreensão sobre o direito a identidade, procurando ir além da tese inicial proposto pela Procuradoria Geral da República (PGR). A proposição inicial tinha como foco pessoas transexuais, os representantes dos amici curie buscando incluir as travestis, sugerindo a mudança para o termo trasngênero, considerado de maior abrangência, de tal modo que incluiria não apenas transexuais, mas outras identidades de gênero como sujeitos de direito dessa ação.

Esse processo indica como o direito é marcado por um processo contínuo de criação de direitos e sujeitos, a partir de sua aplicação à cada caso, sendo, portanto, o sujeito jurídico efeito da jurisprudência. Biehl argumenta que o direito é criação e enquanto arena produz a partir de cada caso, da jurisprudência porque esta " [...] traz a lei para os contextos do mundo real e revela as pessoas e comunidades a partir das suas necessidades e desejos. Ela não depende de um sujeito a priori; pelo contrário, a produção de sujeitos é um efeito da jurisprudência" (SCHUCH, 2016, p. 413, grifo da autora).

Seguindo a perspectiva de estudo de Schuch (2008) sobre o campo judicial em termos de lutas e confrontos de ideias e autoridades, podemos pensar as disputas de sentido e legitimidade de diferentes agentes que se encontram em posições diferentes no campo judicial sobre a demanda de retificação registral, marcados por visões não homogêneas sobre a possibilidade de requalificação registral nas diferentes instâncias do judiciário. Esse processo dinamizado no interior das instituições relacionadas ao campo judicial, em uma rede heterogênea que participam agentes jurídicos, pessoas trans, movimento social e diferentes categorias profissionais que incorporam determinados princípios jurídicos e colocam em disputa diferentes concepções sobre o corpo trans, que levam a decisões favoráveis ou desfavoráveis a retificação do nome e gênero.

Barbarói, Santa Cruz do Sul, Edição Especial n.54, p.<76-93>, jul./dez. 2019 


\section{Nasce um direito: tecnologia de governo e múltiplas controvérsias}

A decisão do STF foi uma importante conquista para a população trans comemorada e discutida em redes sociais, especialmente, no Facebook, além de objeto de matérias jornalística. Em nota pública da ANTRA, lançada na data da decisão da Suprema Corte na página oficial da associação no Facebook, destaca-se que essa decisão marca uma "conquista importante, que nasce da demanda dos movimentos sociais, na luta pelo reconhecimento de nossas identidades, do resgate da cidadania plena e autonomia de nossa população".3

Alessandra Ramos Makkeda, assessora parlamentar de Jean Wyllys na época, ativista trans, publicou na mesma data um post comemorativo, compartilhado 141 vezes, sobre a vitória da população trans, em que destaca que "mudar o nome é uma das coisas mais importantes! Ao fazer isso, o Estado brasileiro reconhece que ser travesti, transexual e transgênero não é algo do outro mundo e reconhece institucionalmente a nossa existência! Isso é o primeiro passo para sermos respeitadas e respeitados e possamos lutar por mais direitos!". ${ }^{4}$

Em entrevista no canal Jornalistas Livres ${ }^{5}$, também publicada no seu perfil dessa mídia alternativa, Alessandra afirma que essa decisão é histórica porque se trata de um momento de reconhecimento, especialmente, de afirmar a existência institucional das pessoas trans. Por isso, a decisão é uma das mais importantes para a população trans porque "definitivamente dá possibilidade de incluir um grupo de pessoas que antes não existia institucionalmente né, na categoria de sujeito de direito" e, portanto, como cidadãos/ãs.

A ênfase dada ao reconhecimento institucional e social e o lugar do ativismo trans para conquistas como essas nas falas da assessora indica que a demanda por direitos perpassa um esforço em tornar-se legível para o Estado, de tal forma que o reconhecimento da identidade através da desjudicialização constitui-se em uma das práticas que possibilita a legibilidade para o Estado e para a sociedade protegendo da violência institucional imposta por portar documento não condizente com a identidade de gênero.

A positivação do direito como um campo necessário e importante para a população LGBT+ e, em especial, para o reconhecimento da identidade foi tema de discussão no evento

\footnotetext{
3 Post da ANTRA publicado na rede social Facebook, no dia 01 de março de 2018. Disponível em: https://www.facebook.com/antrabrasil/posts/1663989877019688. Acesso em: 18 jul. 2019.

${ }^{4}$ Post público de Alessandra Ramos Makkeda, publicado na rede social Facebook, no dia 01 de março de 2018. Disponível em: https://www.facebook.com/alessandra.ramos.makkeda/posts/10156253384772658. Acesso em: 18 jul. 2019.

${ }^{5}$ Post do Jornalistas Livres, publicado na rede social Facebook, no dia 01 de março de 2018. Disponível em: https://www.facebook.com/jornalistaslivres/videos/700878706702676/. Acesso em: 18 jul. 2019.
}

Barbarói, Santa Cruz do Sul, Edição Especial n.54, p.<76-93>, jul./dez. 2019 
Nome e Gênero: O Direito de Ser, realizado na OAB-RS, em Porto Alegre. Foi realizado em agosto de 2018, pela Comissão da Diversidade Sexual e de Gênero da seccional da cidade e contou com as palestrantes Gisele Schimidt, advogada, e Letícia Lanz, psicanalista, ambas mulheres trans. Gisele durante sua breve fala destaca que a decisão por utilizar preceitos internacionais que colocam a identidade de gênero como um direito humano na decisão do STF teve o objetivo de buscar a tutela da dignidade das pessoas trans, conforme previsto no art. 1, inciso III, da Constituição Federal. A advogada foi uma das amici curie nas arguições de votação da ADI 4275 e refere ao participar desse processo teve a oportunidade de presenciar ou "nascimento de um direito lindo [...] porque você vê um direito nascer, um direito que é pleiteado por décadas e décadas e que tantas pessoas trans morreram sem ter o nome, sem serem enterradas com o nome que se identificavam".

Letícia inicia sua fala reforça a discussão de Gisele ao afirmar que o "direito deu um passo gigantesco, abriu fronteiras que a gente nem sonharia que poderíamos abrir tão, a tão curto prazo". Porque diferentemente da medicina, que ainda mantém uma leitura patologizante da transexualidade, o direito avançou. Por isso, é enfática em dizer que gênero não é uma questão médica, mas sim jurídica porque está na base da sociedade, diz respeito a forma como se instituiu social e juridicamente o gênero. A psicanalista destaca que é através dos avanços jurídicos e legislativos que se deve repensar o gênero como afirmação do direito de ser, de existir, explicitado ao afirmar que "é por causa do direito e do feminismo que eu existo", ou seja, "tenho o direito de ser".

A votação da ação direta de inconstitucionalidade, aponta Paulo Iotti, advogado que representou a Associação Brasileira de Gays, Lésbicas, Bissexuais, Travestis, Transexuais e Intersexos (ABGLT) e Grupo de Advogados pela Diversidade Sexual e de Gênero (GADvS) como amicus curie, "foi um dia histórico, de verdadeira libertação da população de travestis, mulheres transexuais e homens trans no Brasil". O efeito dessa decisão marca o reconhecimento da "humanidade, dignidade, cidadania e autonomia das pessoas transexuais e travestis, ao reconhecerem seu direito de soberana autodefinição de sua identidade de gênero e a necessidade de respeito a suas pessoas enquanto tais". 6

As comemorações desses ativistas e entidade representativa da população trans deixam claro a importância dos direitos como uma das dimensões tanto para o movimento de travestis e transexuais, quanto para as experiências cotidianas das pessoas trans ao terem sua existência

\footnotetext{
${ }^{6}$ Paulo Iotti escreve para o portal Justificando. No dia 02 de março de 2018, escreveu o artigo "STF e TSE fazem História ao afirmar a Cidadania de Transexuais e Travestis", trata-se de um longo relato do último dia de votação da ADI 4275, sumarizando os votos de cada Ministro e avaliando os avanços no direito à identidade a partir dessa decisão. Disponível em: https://bit.ly/32Cbxei. Acesso em: 18 jul. 2019.
}

Barbarói, Santa Cruz do Sul, Edição Especial n.54, p.<76-93>,jul./dez. 2019 
reconhecida. A demanda judicial de retificação do registro civil de pessoas trans marcou uma importante linha política dda luta pelo reconhecimento a autodeterminação que se materializou ao longo do processo de julgamento da ADI 4275.

Essa decisão insere-se em um contexto que Rifiotis (2015) chama de judicialização das relações sociais, um termo que designa "os processos que se visibilizam através da ampliação da ação do Estado em áreas de 'problemas sociais' como mecanismo de garantia e promoção de direitos" (idem, p. 266, grifo do autor). Essa movimentação possibilita tanto conformar normas e jurisprudências, como torna-se uma forma dos movimentos sociais visibilizarem e buscarem respostas as suas demandas, chamando a atenção para a centralidade do Direito na leitura dos Direitos Humanos. Constitui-se em um importante elemento na construção da legitimidade das demandas sociais dos movimentos sociais guiadas pela perspectiva dos direitos humanos, conformando normas e jurisprudências e de busca por visibilidade e respostas as suas demandas (RIFIOTIS \& MATOS, 2010; RIFIOTIS, 2014).

O campo jurídico e, especificamente, a Suprema Corte, como deixou claro Paulo Iotti, constituem-se em um campo crítico e de transformação da sociedade através da concretização de "princípios constitucionais e direitos humanos para lutar por um mundo melhor". No constitucionalismo contemporâneo o Judiciário, afirma o advogado, “faz parte da democracia,

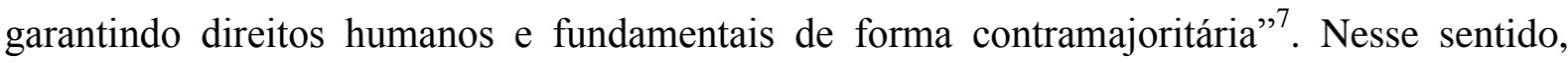
afirma que o STF tem apresentando-se como um espaço fundamental de defesa dos direitos à antidiscriminação, direito à igualdade e à diferença de grupos subalternizados.

Supremo Tribunal Federal tem se mostrado uma importante luz na defesa da população LGBTI contra o heterossexismo e o cissexismo compulsórios (estruturais, sistemáticos e institucionais que são), que proclamam (absurdamente) a "superioridade" da heterossexualidade e da cisgeneridade sobre as distintas orientações sexuais e identidades de gênero. Outras minorias e grupos vulneráveis também têm sido protegidas(os) pelo STF, que tem, assim, cumprido muito bem seu importante papel de proibir opressões pretendidas por maiorias. [...] Isso é algo da essência do constitucionalismo e, nesse ponto, pelo menos quanto a direitos individuais de autonomia privada, tem sido exemplar nossa Suprema Corte, que merece muitos aplausos por resistir ao reacionarismo social e político na proteção destes (cf. artigo "STF e TSE fazem História ao afirmar a Cidadania de Transexuais e Travestis", 2018) (IOTTI, 2018).

\footnotetext{
7 Entrevista realizada com Paulo Iotti para o site Justificando, em 06 de março de 2018. Disponível em: https://bit.ly/2M1YVaM. Acesso em: 18 jul. 2019.
}

Barbarói, Santa Cruz do Sul, Edição Especial n.54, p.<76-93>, jul./dez. 2019 
Nas sociedades democráticas a forma de legitimidade hegemônica reside na crença na legalidade, o que aponta para o processo de judicialização das relações sociais, isto é, a crescente invasão do direito, das leis e do Poder Judiciário na organização da vida social (DEBERT, 2010; RIFIOTIS, 2008, 2014; RIFIOTIS \& MATOS, 2010; SCHUCH, 2008). O discurso dos direitos como um capital simbólico privilegiado no contexto das sociedades democráticas, destaca Schuch (2008), ganha centralidade através de um protagonismo dos órgãos judiciais e passa a compor a linguagem das lutas políticas, pois "na esfera judicial e na esfera extrajudicial do trabalho dos órgãos de justiça, é interessante perceber como a ideia dos 'direitos' passa a se colocar como fundamento para a garantia de elementos básicos para a vida das pessoas, como saúde, liberdade etc.” (SCHUCH, 2008, p. 14).

Essa estratégia de reconhecimento opera, na perspectiva de Biehl (2013), através do que chama de judicialização da biopolítica quando sujeitos passam a demandar do Estado o direito que é garantido constitucionalmente a todos/as. A luta é por formas de inscrição política para participar da gestão política dos corpos. Foucault (2007) havia indicado que, desde o séc. XIX, vem se constituindo uma tecnologia de poder centrada na vida, em que esta se torna objeto de disputas políticas, formulando-se através de reivindicações de direito, como o direito à vida, ao corpo, à saúde, à felicidade, à satisfação das necessidades. Trata-se, diz Fassin (2001), não apenas do controle e regulação, mas também de uma realidade experiencial que compõe as políticas da vida, um território que demarca as fronteiras entre vida nua e vida social, colocando-a como objeto de disputa e como valor entre diferentes atores. As práticas de governo, então, não constituem um conjunto único de controle, mas dependente de uma economia moral que envolve uma rede de diferentes aparatos e agentes.

\section{"Retificação desburocratizada é o babado!"}

No dia em que foi decidido pela desjudicialização no STF, Keila Simpson, presidente da ANTRA, junto com outras ativistas trans realizaram uma fogueira simbólica queimando os laudos psiquiátricos, em comemoração pelo fim da tutela psiquiátrica e psicológica. $\mathrm{Na}$ postagem a ativista afirma que "vc que se acostumou a vender laudos ou ditar como as Travestis e Transexuais deveriam se comportar para obter... Acabou!!!! Segue um vídeo

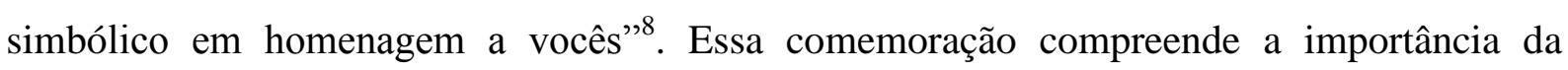
transformação empreendida pela decisão do STF porque reconhece às pessoas trans o direito a

\footnotetext{
${ }^{8}$ Vídeo vinculado no perfil de Keila Simpon no Facebook, no dia 01 de março de 2018. Disponível em: https://www.facebook.com/keila.simpson.9/videos/1622561771161077/. Acesso em: 20 jul. 2019.

Barbarói, Santa Cruz do Sul, Edição Especial n.54, p.<76-93>,jul./dez. 2019
} 
autodeterminação e, especialmente, retira a autoridade de um saber-poder específico para tutelar esse reconhecimento.

A importância é tal que Raíssa realizou uma postagem no Facebook após a sua retificação comemorando o significado desse momento não apenas na sua vida, mas de todas as pessoas trans. E gente: eu não precisei de laudo psicológico. Nem psiquiátrico. Nem endocrinológico. Nem precise passar por nenhum tipo de cirurgia que eu não quisesse.

O MEU CORPO

FOI RECONHECIDO PELO ESTADO

COMO "SEXO FEMININO".

Do jeito que é. E isso é uma parada forte. Em tudo que isso significa. E aí assim véi.. é uma gratidão muito imensa, real, do fundo do meu ser por todas aquelas travestis e pessoas trans que lutaram pra isso se tornar real. Inclusive aquelas que não sobreviveram pra ver esse dia chegar. Hoje foi um dia que eu pensei muito na Kayla, sabe? (quem conheceu, sabe de quem eu to falando).. ELA MERECIA, muito, ter vivido pra esse dia chegar, mas a transfobia tirou isso dela.. Reconhecendo as portas que tudo isso tá me abrindo eu, Raíssa, realmente espero estar à altura do legado que elas me deixaram abrindo caminho pra vida de outras também. A nossa luta continua, e ainda tem muito pra avançar. E LEMBRANDO AMORES: retificação desburocratizada é babado! Mas (1) ainda falta etapas pra se tornar mais acessível (principalmente pra quem não tem renda pra pagar as taxas); (2) pessoas trans que não retificaram CONTINUAM merecendo respeito ao seu nome e sua identidade. E isso INCLUI políticas de nome social, que PERMANECEM necessárias, a gente não pode deixar isso cair não ${ }^{9}$.

Raíssa é enfática a respeito da importância do reconhecimento do Estado através do documento retificado e pela segurança que este apresenta para que não se sofra a negação de sua identidade de gênero. Embora entenda que a afirmação da identidade não depende do Estado, durante nossa conversa a respeito dessa postagem, destaca que para existir em uma sociedade as tecnologias de identificação ainda são necessárias, o que torna o registro do Estado importante. Torna-se importante, especialmente, para aquelas pessoas que estando à margem "(o que implica uma série de vulnerabilidades) o registro civil que a gente tem lá faz toda diferença na forma como a gente vai ser tratada” porque se depende dos serviços estatais para acessar as diferentes políticas e programas sociais.

\footnotetext{
9 Post público feito por Raíssa na rede social Facebook, no dia 24 de julho de 2018. Disponível em: https://www.facebook.com/lesbikaos/posts/611379065928827. Acesso em: 24 jul. 2018.

Barbarói, Santa Cruz do Sul, Edição Especial n.54, p.<76-93>,jul./dez. 2019
} 
Conforme Paulo Iotti, em entrevista ao Justificando, o julgamento do STF tem uma importância histórica para a luta pelo reconhecimento da identidade e da autodeterminação de gênero. A importância foi transcendental. Foi um julgamento histórico que mudou paradigmas, ao permitir a mudança de nome e sexo nos documentos das pessoas transgênero, independente de cirurgia, laudos e de ação judicial. Esse último ponto é simplesmente fenomenal. No Judiciário, depois de um primeiro momento [até os anos 1990], quando não se alterava a alteração nem mesmo com cirurgia - que chamavam de mera "plástica estética", que "não mudava o sexo" e que podia ser contraditório com a (inexistente) proibição do "casamento homossexual" e tudo isso dito em acórdãos do passado -, passou-se a, em algum momento da primeira década dos anos 2000, a consolidarse a permissão à mudança após a cirurgia. Era ainda muito polêmico e minoritária a mudança sem cirurgia, embora a jurisprudência estivesse se direcionando para isso.

A questão da dispensa de laudos quase nunca foi judicializada. Só sei de um caso, a histórica decisão do caso da militante Neon Cunha, em 2016, que pediu isto ou, se fosse negado, pediu que fosse autorizada sua eutanásia, por não aceitar viver sem pleno respeito a sua identidade de gênero. Tenho uma ação que pende de sentença também para dispensar laudos, mas não é um tema que o Judiciário sequer conhece, menos ainda está acostumado. A luta estava começando a engatinhar. A dispensa de ação judicial era fruto de um pedido da Defensoria Pública da União ao CNJ, o qual suspendeu o julgamento até o definitivo deste do STF.

Então, a permissão à mudança sem sequer ação judicial, absolutamente acertada e em consonância com decisão de novembro/2017 da Corte Interamericana de Direitos Humanos [OC 24/17], teve importância transcendental, mudando totalmente o paradigma então vigente. E facilitando muito a vida das pessoas trans, já que muitas não tinham acesso a advogadas ou advogados para tanto, lembrando da ainda precária estrutura das Defensorias Públicas país afora). Não há palavras que traduzam totalmente a importância histórica dessa decisão ${ }^{10}$.

Os discursos médicos e psi patologizantes serviram para conceder e negar direitos, limitando as possibilidades de experiências trans fora do encaixe entre direito e medicina obterem reconhecimento jurídico. A decisão favorável ou não à retificação de nome e gênero era pautada em uma natureza patológica da transexualidade e a expressão de um sofrimento, sendo necessário apresentação de parecer, laudo e outros documentos que comprovassem uma

\footnotetext{
${ }^{10}$ Entrevista realizada com Paulo Iotti para o site Justificando, em 06 de março de 2018. Disponível em: https://bit.ly/2M1YVaM. Acesso em: 18 jul. 2019.
}

Barbarói, Santa Cruz do Sul, Edição Especial n.54, p.<76-93>,jul./dez. 2019 
experiência corporal e psicológica (VENTURA, 2007; COACCI, 2011; LIMA, 2015). Por isso, a articulação e encaixe entre discurso jurídico, médico e psi, como coloca Coacci (2018), influenciou a constituição dos direitos da população trans. A comemoração, portanto, é um contraponto ao modo como se dava esse processo anteriormente, como destaca o advogado, com a entrada na justiça para alcançar o reconhecimento, dependendo de uma perspectiva autorizativa, em que juízes/as, desembargadores/as, profissionais da medicina e/ou psicologia tornavam-se centrais para o deferimento ou não.

Retira-se a mediação de médicos, psicólogos e operadores do direito, mas retira-se a mediação de outros atores? Em princípio, nada mais fácil que ir até o cartório e solicitar a alteração de prenome e gênero na certidão de nascimento. Precisaria apenas tirar um tempo para juntar alguns documentos exigidos, preencher um requerimento e, então, estaria encaminhada a retificação. Os cartórios emitiriam esse novo documento com relativa facilidade cumpridas todas as exigências e o pagamento das taxas. Assim, de posse dessa nova certidão seria necessário apenas regularizar as demais documentações.

Porém, em diversas regiões do país esse processo mostrou-se nada fácil. O período de transição também foi acompanhado de vários debates e embates. Tão logo o Conselho Nacional de Justiça $(\mathrm{CNJ})$ lançou o provimento 73 , regulando a prática dos cartórios em território nacional para a realização das retificações, novas questões surgiram e mais dificuldades.

\section{Garantir a certidão de forma extrajudicial: um procedimento, diferentes formas de regulamentação}

Desde a desjudicialização uma série de notícias apresentando situações em que as pessoas estariam realizando a retificação sem maiores dificuldades. Essas apresentam a importância de um documento retificado no cotidiano das pessoas trans e trazem narrativas de alguma que realizaram o procedimento via cartórios, demonstrando o significado dessa mudança em suas vidas. Do mesmo modo, é destacado a relativa facilidade com que foi realizado o processo, bastando a apresentação de alguns documentos, assinatura de uma declaração e, então, era encaminhado o pedido para a nova certidão retificada que é expedida em cinco dias. ${ }^{11}$

11 Cf. reportagens (1) São Carlos registra 15 mudanças de nome por transgêneros após decisão do STF, de 26/03/2018, disponível em: https://bit.ly/2JI1tJz; (2) Após decisão do STF, trans de Linhares altera nome e gênero no título de eleitor no Cartório, de 05/04/2018, disponível em: https://bit.ly/2XYvo3T; (3) Após novo entendimento do STF, Defensoria faz primeiro mutirão para alterar documentos de trans, de 16/05/2018, disponível em: https://glo.bo/2O6FEYm. Acesso em: 19 jul. 2019.

Barbarói, Santa Cruz do Sul, Edição Especial n.54, p.<76-93>, jul./dez. 2019 
Em alguns casos, essas retificações foram realizadas a partir de mutirões organizados por defensorias públicas, com o objetivo de entregar ofícios de gratuidade e orientações sobre o procedimento. Esse é o caso de Evelyn, primeira mulher trans a realizar a retificação no Rio Grande do Sul, em maio de 2018. Ela contatou diversos cartórios em Porto Alegre, e foi informada que ainda não estavam autorizando a realização do procedimento extrajudicial.

Anteriormente, a decisão do STF ela já havia contatado a Defensoria Pública porque ficou sabendo de um mutirão realizado por esse serviço com o objetivo de pressionar os cartórios a realizarem as retificações. Na época, não conseguiu se fazer presente por questões pessoais. Foi o próprio serviço que a contatou para informar de uma nova possibilidade para a retificação organizada pelo Núcleo de Defesa dos Direitos Humanos da Defensoria Pública (NUDDH-DPERS). Este órgão estava produzindo um ofício com fundamentação jurídica que tinha por objetivo de explicar a mudança com a decisão da Suprema Corte e solicitar que os cartórios a cumprissem. De posse desse documento, Evelyn foi até o cartório da $5^{\mathrm{a}}$ Zona de Porto Alegre, onde conseguiu realizar o procedimento sem dificuldades, embora tivesse que apresentar um número significativo de documentos, entre aqueles que compõem a vida civil, também foi solicitado certidões negativas.

Por ter sido a primeiro do Estado tornou-se um importante marco que foi divulgado em diversas mídias. Evelyn mandou-me cópias de várias reportagens. Essas foram replicadas pela Associação dos Registradores de Pessoas Naturais do Estado do Rio Grande do Sul (ARPEN-RS), especialmente, porque o registrador que realizou a sua retificação, Arioste Schnorr, é presidente da associação. Nas várias entrevistas realizadas, o presidente da associação destaca a importância de o cartório atender adequadamente e fazer cumprir um direito. Para ele, se foi decidido pelo Supremo não restaria dúvidas de que os registradores devem cumprir a decisão, mesmo sem a existência de uma norma regulamentadora de como deverá ser realizada esse processo para pessoas trans. Contudo, destaca que muitos cartórios ainda possuíam dúvidas sobre quando iniciar os processos, dado que o STF não definiu prazo. Por isso, defendiam a necessidade de esperar um provimento com os critérios e documentos a serem exigidos. ${ }^{12}$

\footnotetext{
${ }^{12}$ Cf. reportagens (1) Primeira retificação extrajudicial de prenome e gênero no registro civil de pessoa transexual é realizada mediante atuação do Centro de Referência em Direitos Humanos da Defensoria (RS), disponível em: http://www.arpenrs.com.br/novo/index.php?conteudo=noticia.php\&id=5453, (2) Evelyn Mendes, a primeira trans a retificar o nome em cartório no RS, disponível em: http://www.arpenrs.com.br/novo/index.php?conteudo=noticia.php\&id=5459; (3) Estado faz primeira retificação de nome após decisão do STF, disponível em: http://www.arpenrs.com.br/novo/index.php?conteudo=noticia.php\&id=5511. Acesso em: 19 jul. 2019.
}

Barbarói, Santa Cruz do Sul, Edição Especial n.54, p.<76-93>, jul./dez. 2019 
Nessa época, uma amiga sabendo sobre meu tema de pesquisa encaminha um homem trans para falar comigo, pensando que ele poderia auxiliar na minha pesquisa. Hélio entrou em contato comigo pelo Facebook com várias dúvidas sobre como deveria proceder com relação ao procedimento através dos cartórios. Naquele momento encontrava-se com um processo judicial em andamento para a retificação, por isso e não tinha ideia sobre como proceder. Na primeira vez que havia entrado em contato com o cartório para obter informações sobre o procedimento nos cartórios após a decisão do STF relata que "foram bem estúpidas e falaram que não sabiam de nada, e uma delas que tinha lá meio que deu entender que não iria fazer".

Para auxiliá-lo comentei sobre algumas questões desse período de transição. Por isso, era necessário que ele contatasse diretamente o cartório da cidade onde residia para poder ser mais bem informado. Enquanto fazia isso mantinha-me a par das informações que recebia. Das orientações recebidas, comentou que o atendimento não havia sido satisfatório porque informaram que não realizariam a retificação por enquanto e era para continuar com o processo judicial. Hélio continuou a procura por informações e caminhos para resolver suas questões, conversando com amigos e ligando para outros serviços de garantia de direitos, como o CREAS. No dia seguinte a nossa conversa é lançado o provimento estadual para regulamentar a retificação nos cartórios do Rio Grande do Sul. Com isso, ele cancelou o processo e conseguiu realizar a retificação.

Para entender o porquê da negativa em realizar a retificação nesse cartório entrei em contato com o local. O registrador titular atendeu e expliquei quem eu era e que o objetivo em conversar estava relacionado a minha pesquisa de doutorado. Informou que entendia que o direito havia sido concretizado, mas o trabalho não deveria ser feito a revelia, isto é, conforme o entendimento de cada cartório. Mas sim a partir de uma normativa que orientasse como todos deveriam proceder em território nacional. Por isso, seu cartório não estava realizando porque esperava o lançamento do provimento do CNJ para indicar o modo como deveria ser conduzido a retificação. Para, assim, poder preservar a segurança jurídica, dado que os cartórios tanto trabalham com direito individual e coletivo, prezando pela transparência e publicidade das informações jurídicas.

Comentou sobre dois casos de retificação realizadas em cartórios naquele período, ambos em Porto Alegre. Um deles se tratava do caso de Evelyn e outro realizado em outra zona cartorária. Acredita que no primeiro caso não deveria ter sido realizado porque não havia nenhuma base que pudesse dar segurança jurídica. Já no segundo comenta que o registrador não aceitou fazer e, então, por insistência da pessoa foi encaminhado ao foro de registro Barbarói, Santa Cruz do Sul, Edição Especial n.54, p.<76-93>,jul./dez. 2019 
públicos para o juiz decidir e este negou, bem como o Ministério Público não concordava porque ambos, juiz e promotor, entendiam que não era possível realizar os procedimentos sem provimento que regularizasse-os.

No período de quase quatro meses entre a decisão do STF e o lançamento de uma normativa nacional pelo Conselho Nacional de Justiça (CNJ), o Provimento n. 73, como se viu, não havia padrão nos procedimentos em cartórios. Em diferentes regiões cartórios demandavam documentos diferentes para a emissão de uma nova certidão. Nessa situação, cabia ao titular de cada cartório proceder ou não com a alteração, bem como pela decisão por qual documentação seria exigida.

Em razão dessa diversidade, varas cíveis ou corregedorias de tribunais estaduais lançaram portarias e provimentos que regulamentavam em âmbito municipal ou estadual os procedimentos para a realização da retificação. Em nível estadual foram lançados ao todo oito provimentos, em São Paulo, Rio Grande do Sul, Santa Catarina, Goiás, Rio Grande do Norte, Pará, Pernambuco, Sergipe, Ceará e Maranhão. A documentação exigida em cada um desses provimentos também era diferente. Todos incluíam como obrigatório a apresentação da carteira de identidade e inscrição do cadastro de pessoas física, variando o pedido dos demais documentos: certidão de nascimento, título de eleitor, passaporte, identificação civil nacional (ICN), carteira de nome social ou outro documento com o nome social (opcional), certidões de casamento e de nascimento dos filhos (opcional), comprovante de residência, certidões dos distribuidores cíveis e criminais da justiça estadual e da justiça federal, certidão de distribuição da justiça do trabalho, certidão de execução criminal justiça estadual e federal, certidão da justiça militar (se for o caso), certidão dos tabelionatos de protestos, certidão da justiça eleitoral. Rio Grande do Sul foi o único Estado que solicitou quatro documentos: RG, CPF, Certidão de Nascimento e título de eleitor.

Em alguns provimentos foi ressaltado que a existência de ações cíveis, trabalhistas e criminais não impediria a alteração do prenome e gênero. Goiás foi o único Estado que colocou essa informação como ressalva para impedimento. Do mesmo modo que poucos provimentos colocam como previsão a gratuidade do processo e a autorização para que pessoas registradas em outros Estados pudessem realizar o procedimento nos cartórios da atual residência. Desse modo, as pessoas residentes em um Estado, mas nascida em outro, mesmo quando regulamentado o procedimento, ainda ficaram impedidas de realizá-lo no atual endereço de domicílio, sendo necessário deslocarem-se até a cidade onde foram registradas.

Os diferentes posicionamentos sobre a realização da retificação e variedade de regulamentações levou a ANTRA a produzir um monitoramento para apurar denúncias de Barbarói, Santa Cruz do Sul, Edição Especial n.54, p.<76-93>, jul./dez. 2019 
violação de direito à mudança de nome. Em texto no site oficial da associação informa que tem sido encaminhado diversas denúncias "em que cartórios estariam recusando o cumprimento da decisão do STF, elegendo a não regulamentação pelo CNJ como motivo para o descumprimento. Há ainda casos em que cartórios que estão cumprindo a decisão, mas tem exigido documentos e laudos que contrariam o que ficou decidido pelo STF”. Diante dessas dificuldades as entidades do ativismo trans passaram a realizar atividades para discutir a importância da regulamentação para que se evite abusos ou negativas na realização da alteração de prenome e gênero.

Durante esse processo de lançamento de provimentos estaduais, entidades representativas do movimento LGBT+ tiveram acesso a uma minuta, uma versão provisória do Provimento n. 73, elaborado pela Corregedoria Nacional de Justiça. A controvérsia dizia respeito o impedimento para a retificação em caso de pessoas que possuíssem dívidas ou processos criminais e a presença de laudo como um dos documentos para a realização do procedimento. Nesse contexto, foi produzido documentos com o objetivo de que fosse promulgada uma regulamentação efetivamente emancipatória.

A regulamentação nacional para o procedimento de retificação foi lançada no final de junho de 2018, através do Provimento n. 73. Esse documento ainda é marcado por debates em torno do provimento e controvérsias que surgiram ao longo de sua implementação. Ainda se enfrenta dificuldades pela diversidade de compreensões e operacionalização do procedimento em diferentes cartórios para efetivar a sua realização, seja por dificuldades em obter informações sobre a documentação, gratuidade, exigência de laudo ou na forma de atendimento nos cartórios. 


\section{Considerações finais}

Como se procurou descrever, o direito a identidade é marcado por um campo heterogêneo e dinâmico, marcado por mediações entre atores humanos e não-humanos que produzem as práticas cotidianas do acesso à retificação registral. A mudança promovida pela decisão da Suprema Corte, importante em termos de conquista para a população trans, apresenta novas questões para pensar o Estado e os seus efeitos, considerando que novas autoridades surgem para mediar o processo. Nesse contexto, as pessoas trans agora precisam juntar uma serie de documentos e contar com entendimentos e negociações diversas no cotidiano dos cartórios para que o procedimento seja levado a termo.

Ao apresentar as discussões desenvolvidas nos primeiros meses após a decisão do STF buscou-se acompanhar a processualidade dos direitos e do Estado, acompanhando as discussões e controversias que surgiram após a votação da ação direta de inconstitucionalidade. A desjudicialização apresenta-se como conquista da desburocratização. Por isso, objetivou-se discutir qual o sentido da desburocratização a partir da produção de novas normativas e a organização dos agentes para uma regulamentação que se entende emancipatória. Durante ese proceso diversos entraves não previstos, dúvidas, dificuldades e a formação de redes de solidariedade e ajuda mútua para a realização da retificação foram surgindo com o intuito de dar conta de novas formas de regulação do direito à identidade.

Esse processo marca uma cadeia heterogênea de elementos que produz o direito e os seus sujeitos. Por isso, a trajetória de transformação recente não pode ser pensada enquanto códigos abstratos que seriam aplicados em alguma realidade porque não estão desvinculadas das práticas, atores e instâncias que participam do fazer Estado e dos direitos. À gramática dos direitos articulam-se infraestruturas estatais, mobilizações políticas, dramas morais e sofrimentos, produzindo novos sujeitos de direito.

Nesse sentido, a transformação da regulação do direito e o reconhecimento da identidade insere-se em um contexto mais amplo na biopolítica contemporânea, que tem a presença do Estado e dos direitos para a autodeterminação elementos importantes para a cidadania. Por isso, o processo de cidadanização passa pela continua negociação que envolve práticas administrativas, jurídicas e cotidianas de atores humanos e não-humanos, a partir da atuação de mediadores, como os documentos, legislações, marcos legais internacionais e nacionais, saberes das ciências humanas e médicas, narrativas, ativistas, profissionais, etc. 


\title{
"MY BODY WAS RECOGNIZED BY THE STATE": THE CONTROVERSIES SURROUNDING THE DEJUDICIALIZATION OF THE RIGHT TO IDENTITY
}

\begin{abstract}
The Brazilian context is marked by a legislative gap for access to civil registry corrections for transgender people. The Supreme Court ruling in March 2018 brought a new possibility in the absence of a national regulatory framework for the civil registry rectification process. This decision changes the scenario with the removal of legal and medical tutelage, allowing access to a wider range of subjects who wish to rectify, but not necessarily undergo surgery or diagnostic interviews to obtain a report. Thus, it is understood that this is an advance in the state recognition of gender diversity. In this sense, the objective of this paper is to present some initial questions that emerge from the doctoral field work about the transformation in the process of regulation of the right to identity. We seek to reflect on whether dejudialization implies red tape.
\end{abstract}

Keywords: Trans People; Right to Identity; Dejudicialization.

\section{REFERÊNCIAS}

BIEHL, João. The judicialization of biopolitics: Claiming the right to pharmaceuticals in Brazilian courts. American Ethnologist, v. 40, n. 3, p. 419-436, 2013.

CARRARA, S. Políticas e Direitos Sexuais no Brasil Contemporâneo. Bagoas - Estudos gays: gêneros e sexualidades, n. 05, p. 131-147, 2010.

Moralidades, racionalidades e políticas sexuais no Brasil contemporânea. Rio de Janeiro, Revista Mana, vol. 2, n. 21, pp. 323-345, 2015.

COACCI, Thiago. As engrenagens do poder: sobre alguns encaixes entre direito, ciências e transexualidades no Brasil. Revista ex æquo, n. 38, 2018b. pp. 17-31

A transexualidade no/pelo Judiciário mineiro: um estudo dos julgados do TJMG correlatos à transexualidade no período de 2008 a 2010. Revista Três Pontos, Belo Horizonte, v. 8, n. 2, p.81-92, 2011.

DEBERT, G. G. Desafios da politização da Justiça e a Antropologia do Direito. Revista de Antropologia, São Paulo, USP, v. 53, n. 2, p. 475-492, 2010.

FASSIN, Didier. The biopolitics of otherness: Undocumented foreigners and racial discrimination in French public debate. Anthropology Today, v. 17, n. 1, p. 3-7, 2001.

FREIRE, L. Certificações do sexo e gênero: a produção de verdade nos pedidos judiciais de requalificação civil de pessoas transexuais. Revista Mediações, Londrina, v. 20, n. 1, p. 89$107,2015$.

FOUCAULT, Michel. História da Sexualidade I: a vontade de saber. 18a Ed. Rio de Janeiro: Graal, 2007.

LIMA, L. F. A "verdade" produzida nos autos: uma análise de decisões judiciais sobre retificação de registro civil de pessoas transexuais em Tribunais brasileiros. Dissertação de 
Mestrado (Programa de Pós-Graduação em Antropologia Social), Universidade de São Paulo, São Paulo, 2015.

RIFIOTIS, Theophilos. Judiciarização das relações sociais e estratégias de reconhecimento: repensando a "violência conjugal" e a "violência intrafamiliar". Revista Katálysis, Florianópolis, v. 11, n. 2, p. 225-236, 2008.

Judicialização dos direitos humanos, lutas por reconhecimento e políticas públicas no Brasil: configurações de sujeito. Revista de Antropologia, São Paulo, v. 57, n. 1, p. 119-144, 2014.

Violência, Justiça e Direitos Humanos: reflexões sobre a judicialização das relações sociais no campo da "violência de gênero". Cadernos Pagu, Campinas, a. 45, p. 261-295, 2015 .

; MATOS, M. Judicialização, direitos humanos e cidadania. In: FERREIRA, L. F. G.; ZENAIDE, M. N. T.; PEREIRA, C. M. C.; SILVA, I. N. (Orgs.). Direitos Humanos na Educação Superior: Subsídios para a Educação em Direitos humanos nas Ciências Sociais. João Pessoa: Editora Universitária da UFPB, 2010. p. 241-287.

SCHUCH, Patrice. A “judicialização do amor”: sentidos e paradoxos de uma justiça "engajada", Campos, Curitiba, n. 9, p. 8-29, 2008.

TROUILLOT, Michel Rolph. The Anthropology of the State in the Age of Globalization: Close Encounters of the Deceptive Kind. Current Anthropology, Vol. 42, No. 1, pp. 125-138, 2001.

VENTURA, Miriam. Transsexualismo e respeito à autonomia: um estudo bioético dos aspectos jurídicos e de saúde da "terapia para mudança de sexo". Dissertação de Mestrado apresentada à Escola Nacional de Saúde Pública Sergio Arouca. Rio de Janeiro: 2007.

\section{Sobre a autora:}

Gabriela Felten da Maia é graduada em Psicologia (UFSM), Mestre em Ciências Sociais (PPGCS-UFSM) e atualmente realiza doutoramento em Antropologia Social pela Universidade Federal do Rio Grande do Sul. Desenvolve trabalhos de discussão com educadores sobre gênero e sexualidade na escola, bem como debates sobre a violência de gênero e pesquisas relacionadas à violência, gênero e corporalidades. Endereço Eletrônico: gabryelamaia@gmail.com 